\title{
Update: Interim Guidance for Prevention of Sexual Transmission of Zika Virus - United States, 2016
}

\begin{abstract}
Alexandra M. Oster, MD ${ }^{1}$; Kate Russell, $\mathrm{MD}^{2}$; Jo Ellen Stryker, $\mathrm{PhD}^{1}$; Allison Friedman, $\mathrm{MS}^{3}$; Rachel E. Kachur, $\mathrm{MPH}^{3}$; Emily E. Petersen, $\mathrm{MD}^{4}$;
\end{abstract} Denise J. Jamieson, MD ${ }^{4}$; Amanda C. Cohn, MD ${ }^{5}$; John T. Brooks, MD ${ }^{1}$

On March 25, 2016, this report was posted as an MMWR Early Release on the MMWR website (http://www.cdc.gov/mmwr).

CDC issued interim guidance for the prevention of sexual transmission of Zika virus on February 5, 2016 (1). The following recommendations apply to men who have traveled to or reside in areas with active Zika virus transmission* and their female or male sex partners. These recommendations replace the previously issued recommendations and are updated to include time intervals after travel to areas with active Zika virus transmission or after Zika virus infection for taking precautions to reduce the risk for sexual transmission. This guidance defines potential sexual exposure to Zika virus as any person who has had sex (i.e., vaginal intercourse, anal intercourse, or fellatio) without a condom with a man who has traveled to or resides in an area with active Zika virus transmission. This guidance will be updated as more information becomes available.

Zika virus can be sexually transmitted from a man to his sex partners. Zika virus infection is of particular concern during pregnancy. The first documented case of sexual transmission of Zika virus was in 2008 (2); transmission was from a man to a woman, and sexual contact occurred a few days before the man's symptom onset. The first case of sexual transmission associated with the current outbreak was reported in early February (Dallas County Health and Human Services, unpublished data, 2016). In late February 2016, CDC reported two additional confirmed cases of sexual transmission of Zika virus from men returning from areas with active Zika virus transmission to their sex partners in the United States; these transmissions occurred in early 2016 (3). As of March 18, 2016, CDC has reported three additional cases, for a total of six confirmed cases of sexual transmission in the United States associated with this outbreak. ${ }^{\dagger}$ Another recent report described a case of sexual transmission that occurred in Italy in 2014 (4). In addition, there have been two reports of replication-competent Zika virus isolated from semen at least 2 weeks after onset of illness; blood plasma specimens collected at the same time as the semen specimens tested negative for Zika virus by reverse transcription--polymerase chain reaction (RT-PCR) $(5,6)$. Semen collected from a third man with Zika virus infection had virus particles detectable by RT-PCR at 62 days after fever

\footnotetext{
${ }^{*}$ http://www.cdc.gov/zika/geo/index.html.

${ }^{\dagger}$ http://www.cdc.gov/zika/geo/united-states.html.
}

onset; RT-PCR of blood at that time was negative (7). Because serial semen specimens were not collected for these three cases, the duration of persistence of infectious Zika virus in semen remains unknown.

All reported cases of sexual transmission involved vaginal or anal sex with men during, shortly before onset of, or shortly after resolution of symptomatic illness consistent with Zika virus disease. It is not known whether infected men who never develop symptoms can transmit Zika virus to their sex partners. Sexual transmission of Zika virus from infected women to their sex partners has not been reported. Sexual transmission of many infections, including those caused by other viruses, is reduced by consistent and correct use of latex condoms.

\section{Recommendations for Men and Their Pregnant Partners}

Men who have traveled to or reside in an area with active Zika virus transmission and their pregnant sex partners should consistently and correctly use condoms during sex (i.e., vaginal intercourse, anal intercourse, or fellatio) or abstain from sex for the duration of the pregnancy. This course is the best way to avoid even a minimal risk of sexual transmission of Zika virus, which could have adverse fetal effects when contracted during pregnancy. Pregnant women should discuss their male sex partner's history of travel to areas with active Zika virus transmission and history of illness consistent with Zika virus disease ${ }^{\S}$ with their health care provider; providers can consult CDC's guidance for evaluation and testing of pregnant women (8).

\section{Updated Recommendations}

Recommendations for men and their nonpregnant sex partners. Men and their nonpregnant sex partners (couples) who want to reduce the risk for sexual transmission of Zika virus should use condoms consistently and correctly during sex or abstain from sex. Based on expert opinion and limited but evolving information about the sexual transmission of Zika virus, the recommended duration of consistent condom use or abstinence from sex depends on whether men had confirmed infection or

\footnotetext{
$\$$ Clinical illness consistent with Zika virus disease includes one or more of the following signs or symptoms: acute onset of fever, maculopapular rash, arthralgia, or conjunctivitis.
} 
clinical illness consistent with Zika virus disease and whether men are residing in an area with active transmission (Box). The rationale for selection of these timeframes is available elsewhere (8).

Several factors could influence a couple's level of concern about sexual transmission of Zika virus. The risk for acquiring mosquito-borne Zika virus in areas with active transmission depends on the duration and extent of exposure to infected mosquitoes and the steps taken to prevent mosquito bites. 9 According to currently available information, most Zika virus infections appear to be asymptomatic, and when illness does occur, it is usually mild with symptoms lasting from several days to a week; severe disease requiring hospitalization is uncommon (9). Transmission of Zika virus is of particular concern during pregnancy. Couples who do not desire pregnancy should use available strategies to prevent unintended pregnancy, including use of the most effective contraceptive methods that can be used correctly and consistently (10). In addition, couples should be advised that correct and consistent use of condoms reduces the risk for sexually transmitted infections.

\section{Zika Virus Testing and Sexual Transmission}

At present, Zika virus testing for the assessment of risk for sexual transmission is of uncertain value, because current understanding of the duration and pattern of shedding of Zika virus in the male genitourinary tract is limited. Therefore, neither serum nor semen testing of men for the purpose of assessing risk for sexual transmission is currently recommended.

Zika virus testing is recommended for persons who have had possible sexual exposure to Zika virus and develop signs or symptoms consistent with Zika virus disease. ${ }^{* *}$ A pregnant woman with possible sexual exposure to Zika virus should be tested if either she or her male partner developed symptoms consistent with Zika virus disease (8). CDC urges health care providers to report cases of suspected sexual transmission of Zika virus to local and state health departments.

\footnotetext{
http://www.cdc.gov/zika/prevention.

** http://www.cdc.gov/zika/hc-providers/diagnostic.html.
}

\section{Acknowledgments}

Wafaa El-Sadr, Columbia University, New York, New York; Daniel R. Kuritzkes, Brigham and Women's Hospital, Boston, Massachusetts; Amesh Adalja, UPMC Center for Health Security and University of Pittsburgh School of Medicine, Pennsylvania; Jeffrey Duchin, Public Health-Seattle \& King County, Washington; Trish Perl, Johns Hopkins School of Medicine and Bloomberg School of Public Health, Baltimore, Maryland.
BOX. Recommendations for prevention of sexual transmission of Zika virus for couples in which a man has traveled to or resides in an area with active Zika virus transmission

\section{Couples in which a woman is pregnant}

- Couples in which a woman is pregnant should use condoms consistently and correctly or abstain from sex for the duration of the pregnancy.

\section{Other couples concerned about sexual transmission*}

- Couples in which a man had confirmed Zika virus infection or clinical illness consistent with Zika virus disease should consider using condoms or abstaining from sex for at least 6 months after onset of illness.

- Couples in which a man traveled to an area with active Zika virus transmission but did not develop symptoms of Zika virus disease should consider using condoms or abstaining from sex for at least 8 weeks after departure from the area.

- Couples in which a man resides in an area with active Zika virus transmission but has not developed symptoms of Zika virus disease might consider using condoms or abstaining from sex while active transmission persists.

* Couples who do not desire pregnancy should use the most effective contraceptive methods that can be used correctly and consistently in addition to condoms, which also reduce the risk for sexually transmitted infections. Couples planning conception have a number of factors to consider, which are discussed in more detail in the following: Petersen EE, Polen KN, Meaney-Delman D, et al. Update: interim guidance for health care providers caring for women of reproductive age with possible Zika virus exposure-United States, 2016. MMWR Morb Mortal Wkly Rep 2016. Published online March 25, 2016.

\begin{abstract}
${ }^{1}$ Division of HIV/AIDS Prevention, National Center for HIV/AIDS, Viral Hepatitis, STD, and TB Prevention, CDC; ${ }^{2}$ Epidemic Intelligence Service and Influenza Division, National Center for Immunization and Respiratory Diseases, CDC; ${ }^{3}$ Division of STD Prevention, National Center for HIV/AIDS, Viral Hepatitis, STD, and TB Prevention, CDC; ${ }^{4}$ Division of Reproductive Health, National Center for Chronic Disease Prevention and Health Promotion, CDC; ${ }^{5}$ Office of the Director, National Center for Immunization and Respiratory Disease, CDC.

Corresponding author: Alexandra M. Oster, AOster@cdc.gov, 404-639-6141.
\end{abstract}

\section{References}

1. Oster AM, Brooks JT, Stryker JE, et al. Interim guidelines for prevention of sexual transmission of Zika virus-United States, 2016. MMWR Morb Mortal Wkly Rep 2016;65:120-1. http://dx.doi.org/10.15585/mmwr.mm6505e1

2. Foy BD, Kobylinski KC, Foy JLC, et al. Probable non-vectorborne transmission of Zika virus, Colorado, USA. Emerg Infect Dis 2011;17:880-2. http://dx.doi.org/10.3201/eid1705.101939

3. Hills SL, Russell K, Hennessey M, et al. Transmission of Zika virus through sexual contact with travelers to areas of ongoing transmission - continental United States, 2016. MMWR Morb Mortal Wkly Rep 2016;65:215-6. http://dx.doi.org/10.15585/mmwr.mm6508e2 
4. Venturi G, Zammarchi L, Fortuna C, et al. An autochthonous case of Zika due to possible sexual transmission, Florence, Italy, 2014. Euro Surveill 2016;21:30148. http://dx.doi.org/10.2807/1560-7917. ES.2016.21.8.30148

5. Mansuy JM, Dutertre M, Mengelle C, et al. Zika virus: high infectious viral load in semen, a new sexually transmitted pathogen? Lancet Infect Dis 2016;S1473-3099(16)00138-9.

6. Musso D, Roche C, Robin E, Nhan T, Teissier A, Cao-Lormeau VM. Potential sexual transmission of Zika virus. Emerg Infect Dis 2015;21:359-61. http://dx.doi.org/10.3201/eid2102.141363

7. Atkinson B, Hearn P, Afrough B, et al. Detection of Zika virus in semen[Letter]. Emerg Infect Dis 2016. Published online March 2016. http://dx.doi.org/10.3201/eid2205.160107
8. Petersen EE, Polen KN, Meaney-Delman D, et al. Update: interim guidance for health care providers caring for women of reproductive age with possible Zika virus exposure-United States, 2016. MMWR Morb Mortal Wkly Rep 2016. Published online March 25, 2016.

9. Duffy MR, Chen TH, Hancock WT, et al. Zika virus outbreak on Yap Island, Federated States of Micronesia. N Engl J Med 2009;360:253643. http://dx.doi.org/10.1056/NEJMoa0805715

10. CDC. Contraception. Atlanta, GA: US Department of Health and Human Services, CDC; 2015. http://www.cdc.gov/reproductivehealth/ unintendedpregnancy/contraception.htm 